\title{
SAUDAÇÃO PROFERIDA \\ PELO PROFESSOR JOSE IGNÁCIO BOTELHO DE MESQUITA \\ AO NOVO TITULAR, PROFESSOR FÁBIO NUSDEO
}

Professor Titular Fábio Nusdeo,

Nesta noite, a todos os títulos memorável, entrecruzam-se uma vez mais os caminhos de nossas vidas.

De nosso primeiro encontro, não temos lembranças, temos apenas o testemunho da história, no relato dos nossos pais. Quando nasci, éramos vizinhos, em casas gêmeas, ambas de sua família, no alto da Avenida Angélica, quase tocando a Avenida Paulista. Tive ali e por três meses a minha primeira morada, 0 meu primeiro teto. Conhecendo as relações que se então nutriam entre os bons vizinhos, não seria exagerado presumir que ao transpor pela primeira vez os umbrais daquela casa, houvesse sido saudado por sua família, vindo-me ao encontro exatamente aquele a quem, hoje, pela graça de um feliz destino, ao encontro vou para saudá-lo recebendo-o às portas da Congregação desta Faculdade

Abro-lhe essas portas, hoje, Senhor Professor, de par em par para acolhê-lo fraternalmente, expressar-lhe as boas-vindas e augurar-lhe uma estadia longa, fecunda, enriquecedora tanto para si como para seus alunos e para a própria Academia.

Posso assegurar-lhe, Senhor Professor, pela minha experiência pessoal, que em sua pessoa se reúnem todas as condições necessárias à realização desses desejos. Bem sabe Vossa Excelência que são muitas as condições exigidas para o bom desempenho da tarefa de ensinar. Exige-se inteligência, cultura, educação, paciência, afinco, amor, sensibilidade, equilíbrio, serenidade, mas acima de tudo uma enorme e inesgotável disposição de servir, de pôr-se a serviço do ensino e da ciência.

Esta qualidade, dentre todas, parece-me ser a mais necessária e a măis difícil.

É a mais necessária, porque, sem ela, o ensino e a pesquisa acabam se fazendo apenas para o engrandecimento pessoal do professor, o que constitui um dos piores vícios que pode perverter a formação moral, intelectual e cientifica das 
novas gerações. $\mathrm{O}$ professor comprometido com seu êxito pessoal, antes que o de seus alunos ou da ciência a que se dedicou, facilmente se transforma em um impostor, um fabricante de modas, ao agrado das preferências da época, ou do momento, mas não será nunca um inovador, não cerrará fileiras com aqueles de quem se espera a construção de um mundo melhor.

Esta qualidade não é porém, como disse, apenas a mais necessária, é também a mais dificil. Ela requer virtudes, que se tornam cada vez mais raras.

Essa disposição de servir ao ensino e à pesquisa, demanda uma coragem invencível, inquebrantável, para assumir como valor pessoal, próprio, inalienável, indisponível, a defesa dos fins do ensino e da pesquisa contra os interesses pessoais de natureza econômica e política, que por meio do ensino se pretendem promover.

Valem perfeitamente para os colegiados onde se tomam as decisões em matéria de ensino as críticas que se movem às agências onde se formam as decisões econômicas, conforme a segura exposição de Vossa Excelência. "Os dirigentes das agências governamentais enfatiza o neopluralismo da Public Choice - muito embora possam ter a sua noção a respeito do que venha a ser o interesse público, contemplam outras finalidades mais relevantes para eles, como a segurança no cargo, a carreira, o prestígio, o crescimento da própria agência, a sua remuneração pecuniária, a popularidade do partido a que possam pertencer $e$ demais objetivos da espécie, cujo atendimento visarão a maximizar" (Fundamentos para uma Codificação do Direito Econômico, 1993, p. 121).

A oposição a isto que hoje se chama, eufemisticamente, de viéses e inoperacionalidades e que em outros tempos mais crus, mas também mais verdadeiros atendia a designações bem mais contundentes, demanda disposição de abrir mão da segurança no cargo, da carreira, do prestígio pessoal, sempre que se ponha em causa o interesse público no ensino e na pesquisa.

Ora, meu caro amigo, Professor Titular Fábio Nusdeo, a sua carreira, até aqui, tem-se revelado, neste sentido, exemplar. Poucos dentre os seus pares, poderão exibir, como Vossa Excelência, um elenco tão vasto, rico e significativo, de atividades exercidas no campo de sua especialidade, cujo sentido não é outro senão o de efetivamente servir aos que necessitam de conhecimentos específicos em Direito Econômico. A quantidade e a qualidade de suas contribuições alcançam 
proporções tais que excedem o que normalmente se poderia esperar de um docente, indo colocar-se ao nível da abnegação e da abdicação de toda e qualquer aspiração pessoal, onde se situam isolados os verdadeiros e grandes mestres da ciência e do direito.

A despeito de isolado nessa posição de destaque que seu pertinaz trabalho lhe granjeou, não é Vossa Excelência contudo alguém isolado em relação aos fenômenos que se desenvolvem à sua volta e as angustiantes exigências do seu tempo, às quais tem respondido com um acendrado senso humanístico, firmemente ancorado em legítimas e consistentes aspirações morais.

Impressiona fortemente neste sentido, especialmente aos que como eu acreditam nas virtudes do processo civil e da ciência que o informa, a sua preocupação na concepção de um "Direito Econômico preambular de caráter marcadamente processual, consubstanciado não na norma pela qual se manifesta a ação do Estado sobre o sistema econômico, mas naquela destinada a disciplinar o processo decisório extramercado, de onde surgirá a norma" (ob. cit., p. 156).

A esse respeito, permito-me ressaltar o que parece constituir uma das mais excelsas qualidades de seu pensamento científico, que se deve, senão como não poderia deixar de ser à sua penetrante inteligência dos fenômenos econômicos, certamente à correção moral de seu caráter, que não se deixa embair pelos aspectos mais adulados de uma espécie de panprocessualismo contemporâneo que vem destruindo, senão ameaçando de destruição, as bases sobre que se assenta a liberdade individual.

Observa-se, nos estudos processuais contemporâneos, uma firme tendência de exacerbar, no processo civil, as suas virtudes intrínsecas, não como método para alcançar-se a justa realização de um direito preexistente, mas como instrumento da criação de um direito novo, que dê forma e expressão ao poder detido por aqueles que tenham disponibilidade sobre o processo, transformando-o em modelo para a organização dos interesses de seu grupo, classe, categoria ou partido.

A exaltação aí das virtudes do processo apresenta-se fortemente paradoxal, para não se dizer fingida, pois a outro fim não se dirige senão ao de afastar o império das normas geradas pela via parlamentar, o império das normas criadas por opção política daqueles que para expressá-la foram democraticamente 
eleitos, contrapondo-se-lhe uma normatividade de ocasião, gerada em agências oficiais ou oficiosas, em simpósios, associações, entidades várias de múltiplas feições, mas destituídas sempre de representação institucional ou responsabilidade política perante a nação.

Esse risco nunca passou despercebido a Vossa Excelência, que contra ele disparou certeira advertência: "o próprio procedimento deve estar constantemente sob escrutinio a fim de que, por um vicio funcional interno, não passe a produzir decisões que se apartem consistentemente dos preceitos da moral, da justiça e das próprias bases políticas que sustentam cada sociedade. Localizase aí não o problema de resultados tecnicamente incorretos, ou seja, de decisões errôneas perfeitamente compreensiveis e até mesmo estatisticamente previsiveis, mas de resultados viciados por alguma falha estrutural da mecânica procedimental propriamente dita" (ob. cit., p. 157).

$\mathrm{O}$ vício mais temível do processualismo e do procedimentalismo contemporâneos está exatamente aí; está no ponto que respeita ao sistema de controle da legitimidade das decisões a que o processo conduz. A tendência de se fazer substituir o controle de legitimidade moral, ética ou jurídica, por um controle apenas de oportunidade e conveniência, puramente hedonístico, se apresenta na prática sob a forma de mero lasseamento dos controles de legitimidade, precedido de forte propaganda tendente a minimizar a virtude e a eficácia dos controles de legitimidade, endeusando ao contrário a virtude e a eficácia do senso de justiça ou moral dos donos do processo.

Esses desvãos sombrios que ameaçam o Direito contemporâneo não ameaçam o seu pensamento, a sua construção científica, o seu ensinamento, a sua brilhante, clara, reluzente lição de humanismo, moral, direito e justiça, que nos empolga, nos apaixona, que nos arrebata e nos reafirma, no mais íntimo de nossa alma, a crença nas possibilidades que ainda estão reservadas, nesta Casa, ao ensino e à pesquisa no campo do Direito.

Essa crença, essa esperança, essa justíssima expectativa, Senhor Professor, não se alimentam no entanto, apenas dos frutos imediatos, ainda que talvez os mais saborosos, dos seus mais recentes e culminantes trabalhos. Assentam-se nas expressões assumidas ao longo de um tempo por sua própria vida, que sua obra jurídica simplesmente reflete e placidamente espelha. 
Rodeia-o, Professor, belíssima família que externa, na sua vocação para o Direito, a consideração do trabalho jurídico como tarefa digna de se the dedicar toda uma vida. Esta compreensão e esta sensibilidade não as transmitem os pais aos filhos, senão quando eles próprios, os pais, acima das palavras com que exteriorizam o seu apreço pela profissão que abraçaram, se revelem, por seus atos e obras, verdadeiramente apaixonados pelo mister que exercem. Onde se verá, Senhor Professor, prova mais eloquiente de sua autêntica vocação e leal afeição para o direito, do que na vocação e afeição pelo direito por seus filhos contraída?

O Direito, caro Professor, lhe embala a existência e a dos seus, como as ondas do oceano acariciam as naus dos conquistadores de todos os mares, ou como as ondas da música a elevar os corações aos páramos profundos e iluminados onde só vive e se irradia o puro amor. A sua vida é direito, mas, todos o sabemos, sua vida também é música.

Bem-vindo Professor. Venha trazer-nos o concurso de suas qualidades; de sua capacidade de servir, de sua solidez moral, de sua abnegação aos valores mais puros que informam o Direito, como ciência, como experiência prática, e como ideal, que para sempre valerá a pena ser vivido. 